\title{
Variation of the tidal properties around Gran Canaria
}

\author{
Antonio MARTINEZ ${ }^{\text {a }}$, Esther PEREZ a, Miguel BRUNO ${ }^{\text {b }}$ \\ ${ }^{a}$ Facultad de Ciencias del Mar, Universidad de Las Palmas de Gran Canaria, Canary Islands, Spain \\ ${ }^{b}$ Facultad de Ciencias del Mar, Universidad de Cádiz, Puerto Real, Spain
}

(Received 9 April 1997, revised 3 October 1997, accepted 17 October 1997)

\begin{abstract}
Analysis of water level and current meter series from different locations on the island shelf of Gran Canaria reveals strong variations in tidal properties. Semidiurnal sea level amplitudes agree with the results obtained from global tidal models for this region only on the northern coast of the island, while they decrease towards the southwest $(10 \mathrm{~cm}$ difference for the $M_{2}$ constituent). Semidiurnal currents present maxima at the southeastern and northwestern extremities of the island (30-40 $\mathrm{cm} \mathrm{s}^{-1}$ for $M_{2}$ ) and minima in the north-northeast and southwest (3-6 $\mathrm{cm} \mathrm{s}^{-1}$ for $M_{2}$ ), showing simultaneous strong changes in the phase. Diurnal levels and currents display smaller variations than the semidiurnal band. The behaviour of semidiurnal constituents is studied with the help of analytical and numerical solutions, in which the incident wave is modelled by a barotropic $M_{2}$ Kelvin wave. The results show that the insular shelf could be a source of differences in level amplitudes around the island and could be also responsible for the enhancement of currents in the southeast and northwest. They also show that the variation of the current phases is due to the amplification of the standing character of the wave at the northeastern and southwestern parts of the shelf. () Elsevier, Paris / Ifremer / Cnrs / Ird
\end{abstract}

\section{tide / tidal current / island / numerical modelling / Canary Islands}

Résumé - Variation des propriétés de la marée dans les eaux de la Grande Canarie. L'analyse de séries chronologiques du niveau de la mer et de la courantométrie, en plusieurs points du plateau continental de la Grande Canarie, révèle de grandes variations dans les propriétés de la marée. Les amplitudes des variations semi-diurnes du niveau de la mer sont en accord avec le modèle global de marée au nord de l'île, mais elles diminuent au sud-ouest (de $10 \mathrm{~cm}$ pour la composante $M_{2}$ ). Le courant semi-diurne présente un maximum au sud-est et au nord-ouest de l'île (de 30 à $40 \mathrm{~cm} \mathrm{~s}^{-1}$ pour $M_{2}$ ) et un minimum au nord-nord-est et au sud-ouest (de 3 à $6 \mathrm{~cm} \mathrm{~s}^{-1}$ pour $M_{2}$ ) avec, simultanément, une forte variation de phase. Les variations de période diurne des niveaux et des courants sont plus faibles que celles de période semi-diurne. Les composantes semi-diurnes sont étudiées par des méthodes analytiques et numériques, en considérant que l'onde incidente est une onde barotrope de Kelvin. Les résultats indiquent que le plateau continental est probablement à l'origine des différences observées dans les variations du niveau de la mer autour de l'île et dans le renforcement des courants au sud-est et au nord-ouest. Ils montrent également que la variation de phase du courant est due à l'amplification du caractêre stationnaire de l'onde sur le plateau continental, au nord-est et au sud-ouest de l'île. @ Elsevier, Paris / Ifremer / Cnrs / Ird

marée / courant de marée / île / modélisation numérique / Îles Canaries

\section{INTRODUCTION}

Gran Canaria ( $\left.28^{\circ} 10^{\prime} \mathrm{N}, 15^{\circ} 25^{\prime} \mathrm{W}\right)$ is part of the Canary Archipelago located in the northern part of the Eastern Central Atlantic (figure 1). The island is characterized by a circular form approximately $45 \mathrm{~km}$ in diameter. It pre- sents a narrow shelf that rises sharply from 2000-3000 m depth and is not connected with the neighbouring islands by any common shelf.

Tides in this area arc dominated by the semidiurnal constituents. Tidal maps obtained by the application of 


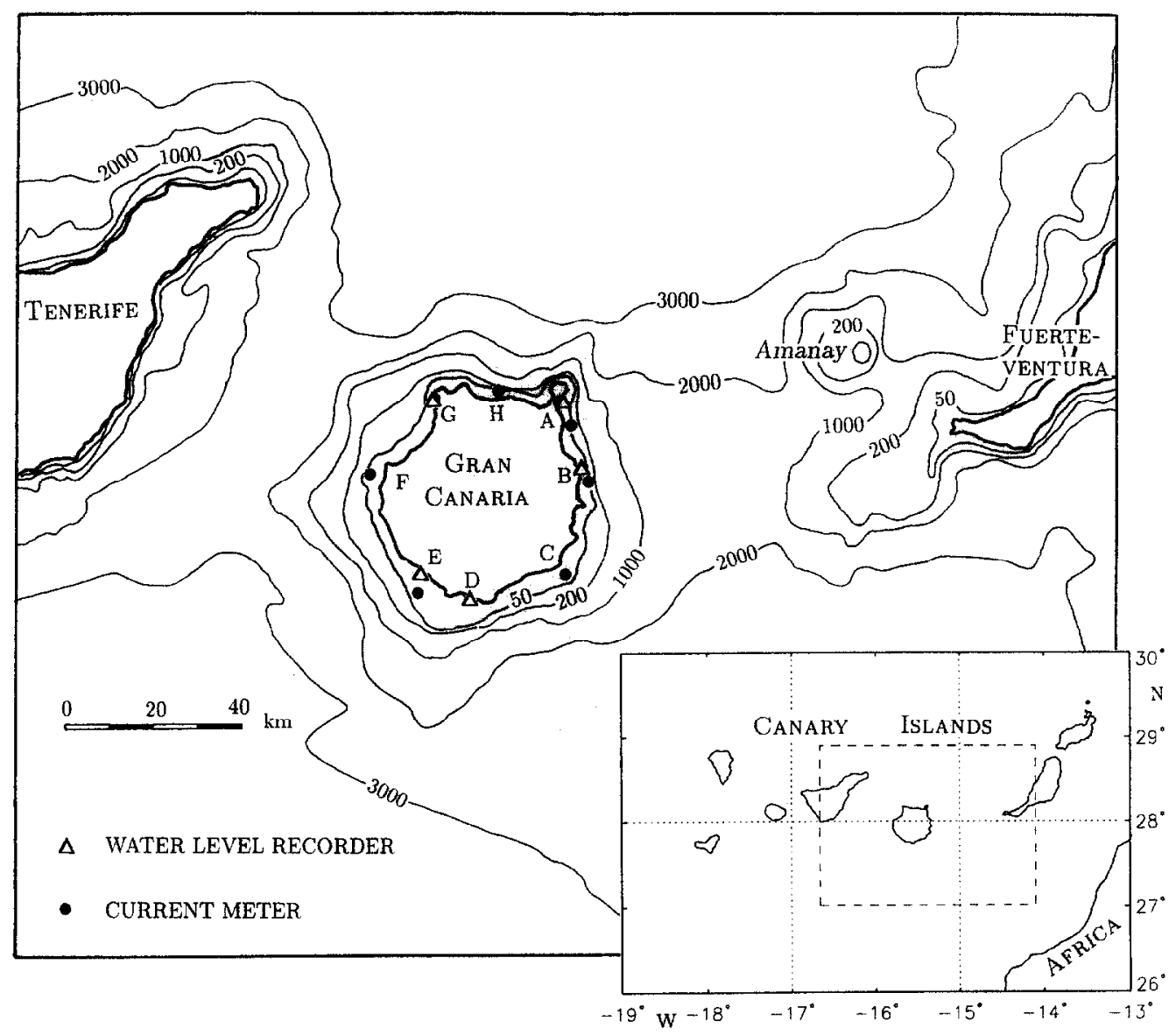

Figure 1. Location map for the Gran Canaria Island showing the positions of the instruments and the bottom bathymetry. Depths in metres.

hydrodynamical equations over the global ocean [21, 24] and maps obtained from a large number of recent models based on Geosat [5] and Topex/Poseidon [2] altimetry data, show that these waves propagate approximately northwards along the African shelf and that the amplitudes increase towards the coast. Analysis of current time series between $21^{\circ}$ and $26^{\circ} \mathrm{N}$ across the slope of the African shelf [15] has shown mooring-averaged semidiurnal currents consistent with a progressive Kelvin wave model. Additionally, Dick and Siedler [7] and Siedler and Paul [25] have studied the semidiurnal tidal currents in the Iberian and Canary basins. Their most relevant findings for the oceanic waters that surround the Canary Islands are that: (a) the tidal currents are dominated by the barotropic mode; (b) the semidiurnal currents oscillate along a direction parallel to the continental slope off northwest Africa; (c) the amplitude of the principal semidiurnal constituent $\left(M_{2}\right)$ is around 3-4 $\mathrm{cm} \mathrm{s}^{-1}$; and (d) the semidiurnal constituents are progressive waves. These results seem to corroborate the conclusion of Huthnance and Baines [15] ascribing the behaviour of semidiurnal tides in this zone to Kelvin waves.

A good understanding of the interaction between tidal waves and oceanic islands is important in order to determine which island data are representative of the deep ocean and consequently which ones are useful in mapping ocean tides. This problem has been recognised by the scientific community [20]. Authors such as Kagan and Kivman $[16,17]$ have studied the representativeness of island tidal measurements, estimating the diffraction disturbances produced in the tidal field without taking into account the effects of the island shelves. In the present work, sea level measurements arc analysed in order to study the amplitude and phase variations of the tidal constituents on the shelf that surrounds Gran Canaria. The study is extended to include the variations of diurnal and semidiurnal currents. This comple- 
ments a further aim of gaining a quantitative understanding of the implications of island tidal currents for biological applications. To explain qualitatively the variations of the tidal properties around the island, the results of a Kelvin wave-forced numerical experiment are presented. The use of these ideal waves allows us to obtain an analytical solution for the diffraction at cylindrical islands and compare it with the numerical results.

The work is organised as follows: the data used and the details of the analysis are described in section 2. The results of the level and current data analysis are given in section 3 . In section 4 an approximation for the diffraction of Kelvin waves at cylindrical islands is presented. The numerical experiments are described in section 5. In section 6 the results of the models and the comparison with the observations are discussed. In section 7 a brief summary of the study is presented.

\section{MEASUREMENTS AND METHODS OF ANALYSIS}

The analysis of tidal oscillations was made with measurements from the island shelf. Station positions around the island, indicated by the letters $\mathrm{A}$ to $\mathrm{H}$, and bottom topography are shown in figure 1. Part of the data used are from various experiments realised between 1986 and 1990 on the east coast of the island [27]. In the present study, previous data have been completed with measurements of sea level at stations $D$ and $G$ and measurements of currents at stations $\mathrm{F}$ and $\mathrm{H}$. Table I abridges the locations, dates, record lengths and depths of the instru- ments. Aanderaa RCM7 current meters were used with recording intervals of between 15 and $30 \mathrm{~min}$. All current meters were deployed between the $40 \mathrm{~m}$ and $50 \mathrm{~m}$ depth contours and at depths of between 15 and $40 \mathrm{~m}$. The longest record is from the 6.5 -month time series of current meter $\mathrm{C}_{\mathrm{A}}-1$. With the exception of station $\mathrm{H}$, where only 12 days of data are available, the series have durations of between 1 and 4 months. The sea level measurements were taken with a WLR5 Aanderaa level recorder. Also in this case, the longest series were collected at station A for 17.5 months, while the other data cover between 1 and 2 months.

The amplitudes and Greenwich phases of the principal tidal constituents for the sea level and the currents were firstly calculated by means of a least square fit harmonic analysis $[9,10]$. This method cannot separate constituents with very similar frequencies when the record length is short. Within the above constituents, there are two pairs of considerable amplitude that cannot be extracted when the series are shorter than six months: the $K_{1}-P_{1}$ and $S_{2}-K_{2}$ pairs. These constituents have been inferred using the values obtained from the analysis of the longest series $\left(W L R_{\mathrm{A}}\right)$.

The amplitudes and phases obtained from the sea level series at station $\mathrm{A}$ were also used to calculate tidal level series for the same observation periods at all other stations. A cross-spectral analysis between computed tidal level series and the observed series was applied, assuming a constant admittance across cach tidal band. The last condition is equivalent to assuming that the ratios of amplitudes and differences of phases between the differ-

Table I. Locations, dates, record lengths and data for water level recorders $(W L R)$ and current meters $(C)$. Subindices correspond to the positions marked in figure 1.

\begin{tabular}{|c|c|c|c|c|c|}
\hline Instrument & Latitude-Longitude & $\begin{array}{c}\text { Date } \\
\text { deployed }\end{array}$ & Days & $\begin{array}{c}\text { Water } \\
\text { depth (m) }\end{array}$ & $\begin{array}{l}\text { Instrument } \\
\text { depth (m) }\end{array}$ \\
\hline$W L R_{A}$ & $28^{\circ} 07.5^{\prime} \mathrm{N}-15^{\circ} 24.8^{\prime} \mathrm{N}$ & 03.02 .89 & 536 & 15 & 15 \\
\hline$W L R_{B}$ & $27^{\circ} 59.2^{\prime} \mathrm{N}-15^{\circ} 22.0^{\prime} \mathrm{N}$ & 14.05 .86 & 50 & 15 & 15 \\
\hline$W L R_{D}$ & $27^{\circ} 45.4^{\prime} \mathrm{N}-15^{\circ} 37.5^{\prime} \mathrm{N}$ & 12.07 .94 & 72 & 2 & 2 \\
\hline$W L R_{E}$ & $27^{\circ} 07.5^{\prime} \mathrm{N}-15^{\circ} 24.8^{\prime} \mathrm{N}$ & 22.01 .88 & 38 & 5 & 5 \\
\hline$W L,_{G}$ & $28^{\circ} 08.6^{\prime} \mathrm{N}-15^{\circ} 42.0^{\prime} \mathrm{N}$ & 10.08 .95 & 74 & 7 & 7 \\
\hline$C_{A^{-1}}$ & $28^{\circ} 05 . \mathrm{YN}-15^{\circ} 23.5^{\prime} \mathrm{N}$ & $18.12-89$ & 201 & 50 & 15 \\
\hline$C_{A}-2$ & $28^{\circ} 05.5^{\prime} \mathrm{N}-15^{\circ} 235^{\prime} \mathrm{N}$ & 18.12 .89 & 124 & 50 & 30 \\
\hline$C_{B^{-}} 1$ & $27^{\circ} 59.0^{\prime} \mathrm{N}-15^{\circ} 21.0^{\prime} \mathrm{N}$ & 23.06 .87 & 29 & 50 & 20 \\
\hline$C_{B}-2$ & $27^{\circ} 59.0^{\prime} \mathrm{N}-15^{\circ} 21.0^{\prime} \mathrm{N}$ & 23.06 .87 & 29 & 50 & 40 \\
\hline$C_{c}$ & $27^{\circ} 47.5^{\prime} \mathrm{N}-15^{\circ} 25.5^{\prime} \mathrm{N}$ & 27.11 .90 & 46 & 40 & 20 \\
\hline$C_{E}$ & $27^{\circ} 45.0^{\prime} \mathrm{N}-15^{\circ} 44.2^{\prime} \mathrm{N}$ & 26.01 .88 & 46 & 40 & 20 \\
\hline$C_{F}$ & $27^{\circ} 59.9^{\prime} \mathrm{N}-15^{\circ} 50.9^{\prime} \mathrm{N}$ & 03.11 .94 & 58 & 45 & 20 \\
\hline$C_{H}$ & $28^{\circ} 10.0^{\prime} \mathrm{N}-15^{\circ} 33.4^{\prime} \mathrm{N}$ & 19.06 .95 & 12 & 40 & 20 \\
\hline
\end{tabular}


ent constituents of each tidal band are the same as those calculated from the longest sea level record (station A). The admittances and phase lags thus obtained have been used to estimate the harmonic constituents for the stations where no 1-year record was availablc. This method 112 , 13] allows the separation of constituents of very close frequencies when these constituents are known in the area. The current analysis is analogous to that of the sea level but for both eastern and northern components of the currents, and is expressed in terms of the ellipse parameters: semi-major $(M)$ and semi-minor ( $m$, negative when the rotation is clockwise) axes, orientation $(\theta)$ defined with respect to the east and increasing anticlockwise, and Greenwich phase lag (G) defined using the northern semi-major axis as reference. Some of the ellipses are oriented roughly east-west, which induce a $180^{\circ}$ uncertainty on the phase. In this case, and in order to be consistent with the literature, a slightly lower than $180^{\circ}$ has been replaced by $\theta-180^{\circ}$ and the associated $\mathrm{G}$ by $\mathrm{G}+180^{\circ}$.

In the study area the inertial frequency falls into the diurnal band $(f=0.0394 \mathrm{c} / \mathrm{h}$ ). Some of the current records show important contributions of near-inertial oscillations (figure 2). This additional contribution affects the diurnal tidal harmonic constants calculated with least square fit analysis, especially the small constituents whose frequencies are between that of $O_{1}$ and $K_{1}$. The harmonic analysis done through admittances is particularly useful for the present study because it allows us to estimate those contributions of only tidal origin.

The temporal series were smoothed previously by means of low-pass filters type $A_{n} A_{n} A_{n}$, [ [11], where the operators An represent successive moving averages of $n$ observations. The response function of these filters is:

$$
F(\sigma)=\frac{\sin ^{2}(n \pi \sigma \Delta t) \sin [(n+1) \pi \sigma \Delta t]}{(n+1) n^{2} \sin ^{3}(\pi \sigma \Delta t)}
$$

which allows the cut-off frequency to be calculated. In the present study the values of $n$ have been chosen according to $n=\Delta t^{-1}$ ( $\mathrm{t}$ in hours), eliminating the frequencies equal and higher than one hour. The use of these filters produces some loss of amplitude in the tidal constituents that has been calculated and recovered by means of function (1).

\section{ANALYSIS RESULTS}

The results obtained for the sea level principal tidal constituents are presented in table II. The phases show that

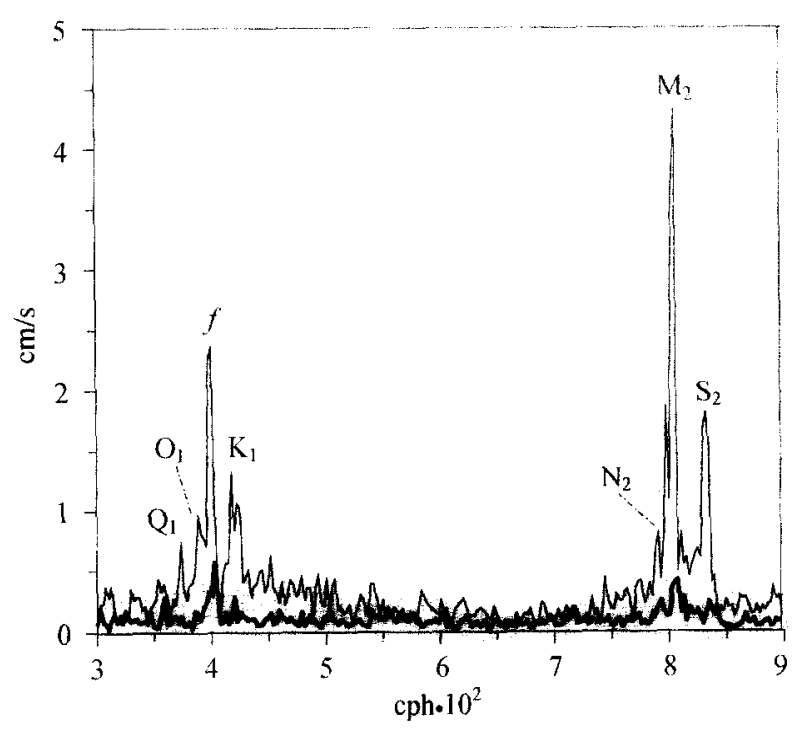

Figure 2. Amplitude spectra (FFT) of the currents parallel (thin line) and normal (thicker line) to the coast in station A. The following peaks are indicated: $M_{2}, S_{2}, N_{2}$ (semidiumal constituents), $K_{t}$, $O_{1}$ (diurnal constituents), and $f$ (inertial frequency).

the progress of the diurnal and semidiurnal waves is approximately from south to north. The higher phase difference for the semidiurnal band is almost $2.7^{\circ}$ between stations $\mathrm{A}$ and $\mathrm{D}$, and $5^{\circ}$ for the diurnal band between stations $\mathrm{A}$ and $\mathrm{E}$. Likewise, the amplitudes of semidiurnal constituents are in accordance with the values shown by the tidal charts of the region $\left(75-76 \mathrm{~cm}\right.$ for $\left.M_{2}\right)$ only at the northern part of the island (stations $A$ and $G$ ). For the remaining stations $(\mathrm{B}, \mathrm{D}$, and $\mathrm{E})$, the amplitudes decrease gradually southwestwards (64 $\mathrm{cm}$ for $M_{2}$ at station E). The amplitudes of the diurnal constituents have similar values at every station, with a slight tendency to increase towards the southwest.

The results of the current analysis for the principal diurnal $\left(K_{1}\right)$ and semidiurnal $\left(M_{2}\right)$ constituents are presented in table III, which shows that the currents oscillate principally along the direction parallel to the island coast. In addition, the reader can see the differences displayed by the semidiurnal current amplitudes around the island. At the north-northeastern $(\mathrm{H}, \mathrm{A}$, and $\mathrm{B})$ and southwestern (E) stations, the semi-major axes are relatively small, while at the southeastern and western stations ( $\mathrm{C}$ and F) they are considerably larger, by about one order of magnitude. The semi-major axis of the dominant constituent $M_{2}$ increases from 2-3 $\mathrm{cm} \mathrm{s}^{-1}$ at the southwestern and northern extremities of the island, to $40 \mathrm{~cm} \mathrm{~s}^{-1}$ in the southeastern (station $\mathrm{C}$ ) and $28 \mathrm{~cm} \mathrm{~s}^{-1}$ in the west 
Table II. Amplitudes (A) and phases (G) with respect to GMT of the principal constituents of the sea level at different sites around Gran Canaria. Results obtained from a least square fit are indicated in parentheses and the results obtained through admittances are presented without parenthesis.

\begin{tabular}{|c|c|c|c|c|c|c|c|c|c|c|}
\hline \multirow[t]{2}{*}{ Cons. } & \multicolumn{2}{|c|}{$W L R_{A}$} & \multicolumn{2}{|c|}{$W L R_{B}$} & \multicolumn{2}{|c|}{$W L R_{D}$} & \multicolumn{2}{|c|}{$W L R_{E}$} & \multicolumn{2}{|c|}{$\boldsymbol{W L} \boldsymbol{R}_{G}$} \\
\hline & $\boldsymbol{A}$ & $G$ & $\boldsymbol{A}$ & $G$ & $A$ & $G$ & $\boldsymbol{A}$ & $G$ & $A$ & $G$ \\
\hline$O_{1}$ & $(4.9)$ & $(292.4)$ & $\begin{array}{c}4.7 \\
(4.6)\end{array}$ & $\begin{array}{c}292.1 \\
(295.1)\end{array}$ & $\begin{array}{c}5.0 \\
(4.4)\end{array}$ & $\begin{array}{c}288.0 \\
(288.7)\end{array}$ & $\begin{array}{c}5.6 \\
(5.0)\end{array}$ & $\begin{array}{c}287.1 \\
(287.0)\end{array}$ & $\begin{array}{c}5.0 \\
(5.0)\end{array}$ & $\begin{array}{c}290,3 \\
(290.6)\end{array}$ \\
\hline$K_{i}$ & $(6.2)$ & $(40.3)$ & $\begin{array}{c}6.0 \\
(6.3)\end{array}$ & $\begin{array}{c}39.0 \\
(38.8)\end{array}$ & $\begin{array}{c}6.4 \\
(6.8)\end{array}$ & $\begin{array}{c}35.9 \\
(37.2)\end{array}$ & $\begin{array}{l}7.1 \\
(6.3)\end{array}$ & $\begin{array}{c}34.9 \\
(38.1)\end{array}$ & $\begin{array}{c}6.3 \\
(6.7)\end{array}$ & $\begin{array}{c}38.2 \\
(40.2)\end{array}$ \\
\hline $\mathrm{N}_{2}$ & $(15.5)$ & $(14.0)$ & $\begin{array}{c}15.0 \\
(15.2)\end{array}$ & $\begin{array}{c}13.4 \\
(11.0)\end{array}$ & $\begin{array}{c}13.8 \\
(11,9)\end{array}$ & $\begin{array}{c}11.4 \\
(13.6)\end{array}$ & $\begin{array}{c}13.1 \\
(17.2)\end{array}$ & $\begin{array}{c}12.0 \\
(15.7)\end{array}$ & $\begin{array}{c}15.5 \\
(13.8)\end{array}$ & $\begin{array}{c}15.0 \\
(104)\end{array}$ \\
\hline$M_{2}$ & $(75.7)$ & $(27.0)$ & $\begin{array}{c}73.3 \\
(73.7\end{array}$ & $\begin{array}{c}26.4 \\
(26.0)\end{array}$ & $\begin{array}{c}67.6 \\
(67.6)\end{array}$ & $\begin{array}{c}24.4 \\
(24.6)\end{array}$ & $\begin{array}{c}64.3 \\
(63.9)\end{array}$ & $\begin{array}{c}25.0 \\
(24.9)\end{array}$ & $\begin{array}{c}76.2 \\
(75.6)\end{array}$ & $\begin{array}{c}28.0 \\
(28.9)\end{array}$ \\
\hline$S_{2}$ & (28.6) & (49.6) & $\begin{array}{c}27.7 \\
(27.0)\end{array}$ & $\begin{array}{c}49.0 \\
(53.5)\end{array}$ & $\begin{array}{c}24.5 \\
(24.9)\end{array}$ & $\begin{array}{c}47.0 \\
(43.5)\end{array}$ & $\begin{array}{l}47.00 \\
(43.5)\end{array}$ & $\begin{array}{c}24.3 \\
(26.8)\end{array}$ & $\begin{array}{c}28.8 \\
(28.5)\end{array}$ & $\begin{array}{l}50.46 \\
(47.3)\end{array}$ \\
\hline$K_{2}$ & $(8.6)$ & $(48.7)$ & $\begin{array}{c}8.4 \\
(8.1)\end{array}$ & $\begin{array}{c}48.1 \\
(52.7)\end{array}$ & $\begin{array}{c}7.7 \\
(7.5)\end{array}$ & $\begin{array}{c}46.1 \\
(42.6)\end{array}$ & $\begin{array}{c}7.4 \\
(8: 1)\end{array}$ & $\begin{array}{c}46.7 \\
(46.0)\end{array}$ & $\begin{array}{c}8.7 \\
(8.6)\end{array}$ & $\begin{array}{c}49.7 \\
(46.4)\end{array}$ \\
\hline
\end{tabular}

(station F). However, the semi-major axes of the diurnal constituents are similar at every station (between 1.4 and $2.4 \mathrm{~cm} \mathrm{~s}^{-1}$ for the principal diurnal constituent $K_{2}$ ), maxima being observed at stations $\mathrm{C}$ and $\mathrm{F}$.

Current phases also show an important variation around the island. In order to study the origin of the variation, the tidal constituents have been decomposed into progressive and standing waves by inter-comparison of the current phases with the phases of the surface elevation, a method frequently used to characterize the tides $[23,7]$.
In the case of progressive waves, currents and surface elevation should be in phase, while in the case of standing waves they will have a $90^{\circ}$ phase shift. The procedure consists of choosing the time of local high water as the origin time, so that the sea level displacement due to a component of frequency has the form $A \cos \sigma t$. Hence the current velocity $\mathrm{V}$ can be written as:

$$
\begin{gathered}
\mathrm{V}(t)=W_{E} \cos \left(\sigma t-G_{E}^{\prime}\right)+i W_{E} \cos \left(\sigma t G_{N}^{1}\right) \\
\left(W p_{E}+i W p_{N}\right) \cos \sigma t+\left(W s_{E}+i W s_{N}\right) \sin \sigma t
\end{gathered}
$$

Table III. Semi-major $(M)$ and semi-minor $(\mathrm{m})$ axes in $\mathrm{cm} \mathrm{s}^{-1}$, orientation with respect to the east $(\theta)$ and phase with respect to GMT (G) of the principal diurnal $\left(K_{1}\right)$ and semidiurnal $\left(M_{2}\right)$ ellipses. The results obtained from a least square fit are indicated within parentheses and the

\begin{tabular}{|c|c|c|c|c|c|c|c|c|}
\hline \multirow{2}{*}{$\begin{array}{l}\text { Current } \\
\text { meter }\end{array}$} & \multicolumn{4}{|c|}{$K_{1}$} & \multicolumn{4}{|c|}{$\boldsymbol{M}_{2}$} \\
\hline & $M$ & $m$ & $\theta$ & $G$ & $M$ & $m$ & $\theta$ & $G$ \\
\hline$C_{A^{-1}}$ & $\begin{array}{c}1.4 \\
(2.1)\end{array}$ & $\begin{array}{c}-0.1 \\
(-0.1)\end{array}$ & $\begin{array}{c}72.9 \\
(75.5)\end{array}$ & $\begin{array}{c}7.6 \\
(13.1)\end{array}$ & $\begin{array}{c}5.9 \\
(6.2)\end{array}$ & $\begin{array}{c}-0,3 \\
(-0.4)\end{array}$ & $\begin{array}{c}74.0 \\
(73.7)\end{array}$ & $\begin{array}{c}279.0 \\
(274.0)\end{array}$ \\
\hline$C_{A^{-2}}$ & $\begin{array}{c}1.4 \\
(20)\end{array}$ & $\begin{array}{l}-0.1 \\
(0.2)\end{array}$ & $\begin{array}{c}79.6 \\
(77.2)\end{array}$ & $\begin{array}{l}353.0 \\
(2.4)\end{array}$ & $\begin{array}{c}6.1 \\
(6.3)\end{array}$ & $\begin{array}{c}-0.2 \\
(-0.2)\end{array}$ & $\begin{array}{c}81.5 \\
(81.7)\end{array}$ & $\begin{array}{c}284.0 \\
(277.6)\end{array}$ \\
\hline$C_{B^{-2}}$ & $\begin{array}{c}1.5 \\
(1.6)\end{array}$ & $\begin{array}{c}0.0 \\
(0.2)\end{array}$ & $\begin{array}{c}80.6 \\
(88.0)\end{array}$ & $\begin{array}{c}53.7 \\
(41.0)\end{array}$ & $\begin{array}{c}9.3 \\
(8.6)\end{array}$ & $\begin{array}{l}2.9 \\
(2.6)\end{array}$ & $\begin{array}{c}53.5 \\
(54.8)\end{array}$ & $\begin{array}{c}282.8 \\
(280.0)\end{array}$ \\
\hline$C_{B}-2$ & $\begin{array}{c}1.2 \\
(1.7)\end{array}$ & $\begin{array}{c}0.1 \\
(0.4)\end{array}$ & $\begin{array}{c}72.8 \\
(74.8)\end{array}$ & $\begin{array}{c}40.5 \\
(45.0)\end{array}$ & $\begin{array}{c}9.4 \\
(9.5)\end{array}$ & $\begin{array}{l}2.0 \\
(1.4)\end{array}$ & $\begin{array}{c}45.2 \\
(43.2)\end{array}$ & $\begin{array}{c}283.5 \\
(283.1)\end{array}$ \\
\hline$C_{c}$ & $\begin{array}{c}2.4 \\
(3.0)\end{array}$ & $\begin{array}{c}-0.3 \\
(-0,2)\end{array}$ & $\begin{array}{c}36.9 \\
(33.3)\end{array}$ & $\begin{array}{c}32.8 \\
(38.5)\end{array}$ & $\begin{array}{c}41.4 \\
(42.0)\end{array}$ & $\begin{array}{c}1.8 \\
(1.0)\end{array}$ & $\begin{array}{c}30.2 \\
(29.5)\end{array}$ & $\begin{array}{c}13.8 \\
(14.6)\end{array}$ \\
\hline$C_{E}$ & $\begin{array}{c}2.0 \\
(3.3)\end{array}$ & $\begin{array}{c}-0.1 \\
(-0.1)\end{array}$ & $\begin{array}{c}137.1 \\
(137.2)\end{array}$ & $\begin{array}{c}34.2 \\
(64.1)\end{array}$ & $\begin{array}{c}2.8 \\
(2.9)\end{array}$ & $\begin{array}{c}0.1 \\
(0.1)\end{array}$ & $\begin{array}{c}141.5 \\
(140.3)\end{array}$ & $\begin{array}{c}122.3 \\
(127.6)\end{array}$ \\
\hline$C_{F}$ & $\begin{array}{c}2.4 \\
(2.7)\end{array}$ & $\begin{array}{c}0.1 \\
(0.1)\end{array}$ & $\begin{array}{c}76.8 \\
(77.3)\end{array}$ & $\begin{array}{c}95.2 \\
(126.2)\end{array}$ & $\begin{array}{c}27.9 \\
(27.9)\end{array}$ & $\begin{array}{c}4.3 \\
(4.2)\end{array}$ & $\begin{array}{c}62.9 \\
(62.8)\end{array}$ & $\begin{array}{r}326.9 \\
(326.9)\end{array}$ \\
\hline$C_{H}$ & 1.4 & -0.1 & 4.2 & 70.3 & 2.7 & -0.2 & 179.7 & 139.5 \\
\hline
\end{tabular}
results obtained through admittances are presented without parentheses. 
where $\left(W_{E}, W_{N}\right)$ are the east-west and north-south observed amplitudes of the currents $\left(G_{E}^{1}, G_{N}^{1}\right)$ the phase lags, $\left(W p_{E}, W p_{N}\right)$ the progressive components, and $\left(W s_{F}\right.$, $W s_{N}$ ) the standing wave components. The amplitudes of progressive $W p=\left(W p_{E}^{2}+W p_{N}^{2}\right)^{1 / 2}$ and of standing $W s=\left(W s_{E}^{2}+W s_{N}^{2}\right)^{1 / 2}$ waves computed in this way for the $K_{1}$ and $M_{2}$ constituents are presented in table $I V$. The standing wave for the $M_{2}$ constituent is the dominant one at the southwestern and north-northwestern stations ( $\mathrm{A}, \mathrm{B}, \mathrm{E}$, and $\mathrm{H}$ ). The progressive wave enlarges at station $F$ and dominates at station $C$. The variation of the ratio $W s /(W p+W s)$ for $K_{1}$ is smaller than that of $M_{2}$, however, they show a similar pattern: the ratio presents two maxima at stations $\mathrm{A}$ and $\mathrm{F}$.

\section{BASIC EQUATIONS AND ANALYTICAL APPROXIMATION FOR KELVIN WAVE DIFFRACTION}

The vertically-integrated equations of momentum and conservation of mass in a Cartesian coordinate system (neglecting horizontal viscosity terms) has the form:

$$
\begin{aligned}
& \frac{\partial u}{\partial t}+u \frac{\partial u}{\partial x}+v \frac{\partial u}{\partial y}-f v=-g \frac{\partial \eta}{\partial x}-k \frac{u \sqrt{u^{2}+v^{2}}}{h+\eta} \\
& \frac{\partial v}{\partial t}+u \frac{\partial v}{\partial x}+v \frac{\partial v}{\partial y}+f u=-g \frac{\partial \eta}{\partial y}-k \frac{v \sqrt{u^{2}+v^{2}}}{h+\eta} \\
& \frac{\partial \eta}{\partial t}=-\frac{\partial[u(h+\eta)]}{\partial x}-\frac{\partial[v(h+\eta)]}{\partial y}
\end{aligned}
$$

where $\eta$ is the surface elevation, $u$ and $v$ are the depth averaged horizontal velocity components, $g$ is the accel- eration due to gravity, $h$ is the depth, and $k$ is the bottom friction coefficient.

With the objective of obtaining an analytical solution. cylindrical coordinates have been used $(r ; \theta$ stand for the radial and angular directions, respectively) with the island contour represented by a circular cylinder of radius $r_{a}$. The inviscid linearized version of the equations (3)-(5) for harmonic motion, $\eta=Z(r, \theta) \exp (i \sigma t)$ in a uniformlyrotating plane ocean lead to the Helmholtz equation [18]: $\left(\nabla^{2}+k^{2}\right) Z=0$ where $k^{2}=\left(\sigma^{2}-f^{2}\right)(g h)^{-1}$. The $r$ and $\theta$ components of the currents are, respectively, $v_{\mathrm{r}}=V_{\mathrm{r}} \exp (i \sigma t)$ and $v_{\theta}=V_{\theta} \exp (i \sigma t)$ where:

$$
\begin{aligned}
& V_{r}=\frac{g}{\sigma^{2}-f^{2}}\left[i \sigma \frac{\partial Z}{\partial r}+\frac{f}{r} \frac{\partial Z}{\partial \theta}\right] \\
& V_{\theta}=\frac{i g}{\sigma^{2}-f^{2}}\left[i f \frac{\partial Z}{\partial r}+\frac{\sigma}{r} \frac{\partial Z}{\partial \theta}\right]
\end{aligned}
$$

Proudman [22] and later Larsen [19] studied the diffraction of Sverdrup waves of tidal frequencies at islands, showing that the interaction between tidal waves and islands leads to the appearance of scattered waves. The complete solution of the Helmholtz equation for the scattered wave is:

$$
Z_{s}=\sum_{n=-\infty}^{\infty} B_{n} H_{n}^{(1)}(k r) \exp (-i n \theta)
$$

where $Z_{s} \rightarrow 0$ when $r \rightarrow \infty$.

$H_{n}^{(1)}$ are Hankel functions, and $B_{n}$ are constants. Since

\begin{tabular}{|c|c|c|c|c|c|c|}
\hline \multirow{2}{*}{$\begin{array}{l}\text { Current } \\
\text { meter }\end{array}$} & \multicolumn{3}{|c|}{$K_{1}$} & \multicolumn{3}{|c|}{$M_{2}$} \\
\hline & $W p$ & $W s$ & $W s /(W p+W s)$ & $W p$ & Ws & $W s /\left(W_{p}+W s\right)$ \\
\hline$\overline{C_{A^{-1}}}$ & 1.18 & 0.76 & 0.39 & 1.80 & 5.42 & 0,75 \\
\hline$C_{A}-2$ & 1.19 & 1.29 & 0.52 & 1.31 & 5.69 & 0.81 \\
\hline$C_{B}-2$ & 1.46 & 0.35 & 0.19 & 3.50 & 8.70 & 0.71 \\
\hline$C_{B^{-}}-2$ & 1.19 & 0.05 & 0.04 & 5.07 & 7.94 & 0.61 \\
\hline$C_{c}$ & 2.34 & 0.42 & 0.15 & 38.84 & 9.29 & 0.19 \\
\hline$C_{E}$ & 1.90 & 0.25 & 0.12 & 0.28 & 2.65 & 0.90 \\
\hline$C_{F}$ & 1.35 & 1.92 & 0.59 & 16.00 & 22.00 & 0.58 \\
\hline$c_{H}$ & 1.24 & 0.69 & 0,36 & 1.00 & 2.39 & 0.71 \\
\hline
\end{tabular}
the radius of the island is small compared to the wavelength, the form of the scattered wave is dominated by the $n= \pm 1$ modes with $H_{1}^{(1)} \approx-i Y_{1}, Y$ denoting a Neuman function.

Table IV. Amplitudes in $\mathrm{cm} \mathrm{s}^{-1}$ of the standing (Ws) and progressive (Wp) components of $\mathrm{K}_{1}$ and $M_{2}$. 
The observations made in the open ocean near the Canary Islands, described in section 1, indicate that the semidiurnal constituents in this area are similar to Kelvin waves. Therefore, in order to study qualitatively the fundamental mechanisms that determine the behaviour of the tide at the insular shelf, the principal semidiurnal wave $M_{2}$ away from the island will be, from now on, approximated by a Kelvin wave. The diffraction of the Kelvin wave $\left(Z_{k}\right)$ travelling in the positive $x$ direction, in cylindrical coordinates (using $x=r \cos \theta$ and $y=r \sin \theta$ ), can be approximated by:

$$
\begin{aligned}
& Z=Z_{k}+Z_{s} \approx A \exp \left[-r\left(i k_{0} \cos \theta+\sin \theta\right)\right] \\
& +Y_{1}(k r)(C \sin \theta+D \cos \theta)
\end{aligned}
$$

where $C=i\left(B_{1}-B_{-1}\right)$ and $D=\left(B_{1}+B_{-1}\right), k_{\mathrm{n}}=\sigma(g h)^{-1 / 2}$ is the Kelvin wave number, and $m_{0}=f(g h)^{-1 / 2}$ is the inverse of the Rossby radius of deformation.

At the island boundary $k_{\mathrm{o}} r_{\mathrm{a}} \ll 1$ and $m_{\mathrm{o}} r_{\mathrm{a}}<<1$, which imply $k r_{\mathrm{a}} \ll<1$ and $Y_{\mathrm{1}}\left(k r_{\mathrm{a}}\right) \approx-2 i / \pi k r_{\mathrm{a}}$ [1]. Then the solution can be approximated by the following linear functions along the radial direction: $Z_{k} \approx A\left[1-r_{\mathrm{a}}\left(i k_{0} \cos \theta+m_{\mathrm{o}}\right.\right.$ $\sin \theta)]$ and $Z_{s} \approx-i 2(C \sin \theta+D \cos \theta) / \pi k r_{\mathrm{a}}$. The coefficients are then readily evaluated applying the boundary condition of null velocity normal to the coast:

$C=i \frac{\pi}{2} A k r_{a}^{2} m_{0} ; D=\frac{\pi}{2} A k r_{a}^{2} k_{0}$

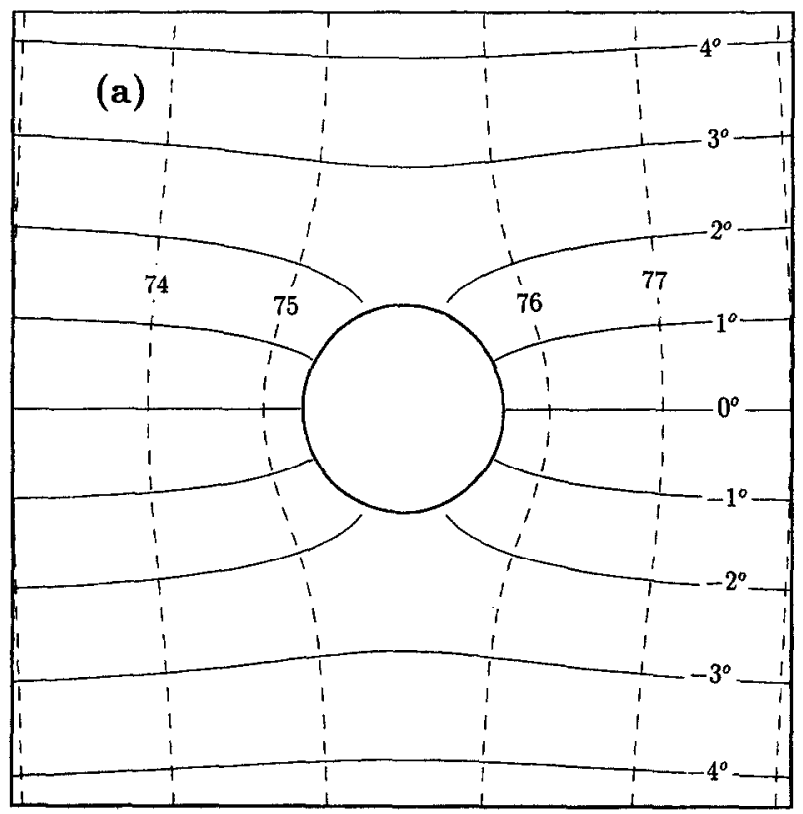

We have calculated the function $\mathrm{Z}$ at the local latitude for a water depth $h=3000 \mathrm{~m}$ and for an island of $23 \mathrm{~km}$ radius, which is approximately that of Gran Canaria. Figure $3 a$ shows the resulting contours of amplitude and phase lag. The scattered wave produces a diminution of the amplitude on the right side of the island and an enlargement at the left, looking in the direction of the wave propagation. This effect compensates approximately the variation in amplitude of the incident Kelvin wave, producing almost constant amplitudes around the cylinder.

The tidal currents can be calculated with equation (6). They are a somewhat complicated function of the cylindrical coordinates, but the tidal ellipses were found to have negligible semi-minor axes around the island. Figure $3 b$ shows the results for the current amplitudes. They change around the cylinder so that the minimum amplitudes are located at the front and back of the island while the maximum amplitudes are found at both sides (looking at the cylinder in the wave direction).

\section{DESCRIPTION OF THE NUMERICAL EXPERIMENTS}

Several numerical experiments were performed considering the incoming $M_{2}$ tide as a Kelvin wave. The equations (3)(5) were integrated numerically with an explicit finite dif-

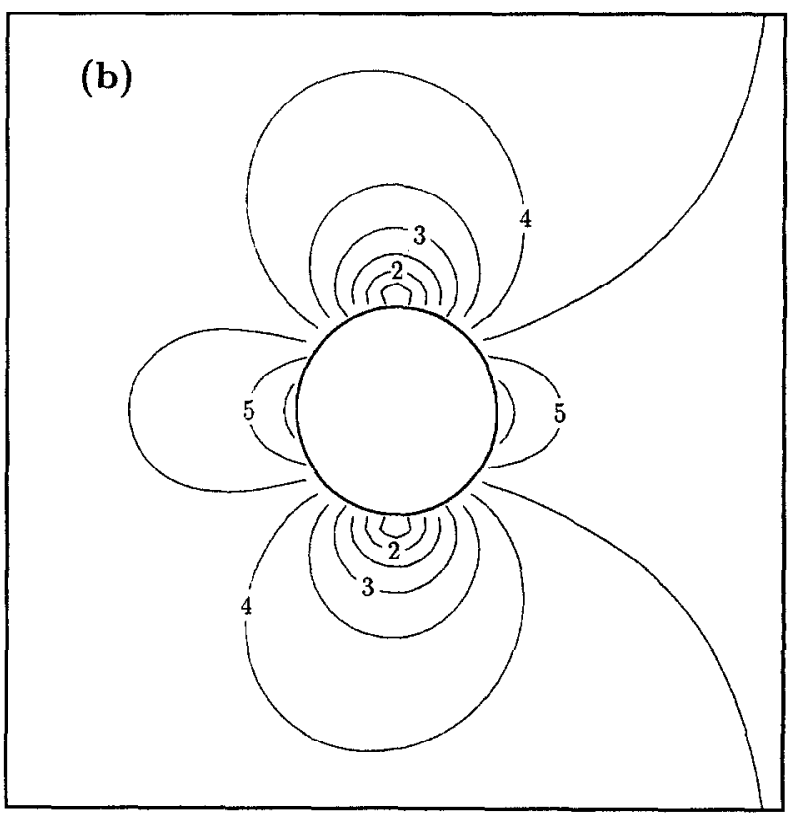

Figure 3. Analytical result for the diffraction of a Kelvin wave (progressing towards the top) due to a circular cylinder of radius $23 \mathrm{~km}$. (a): vertical displacement $(\eta)$. Continuous lines: phases. Dashed lines: amplitudes in $\mathrm{cm}$. (b): current amplitudes in $\mathrm{cm} \mathrm{s}^{-1}$. 

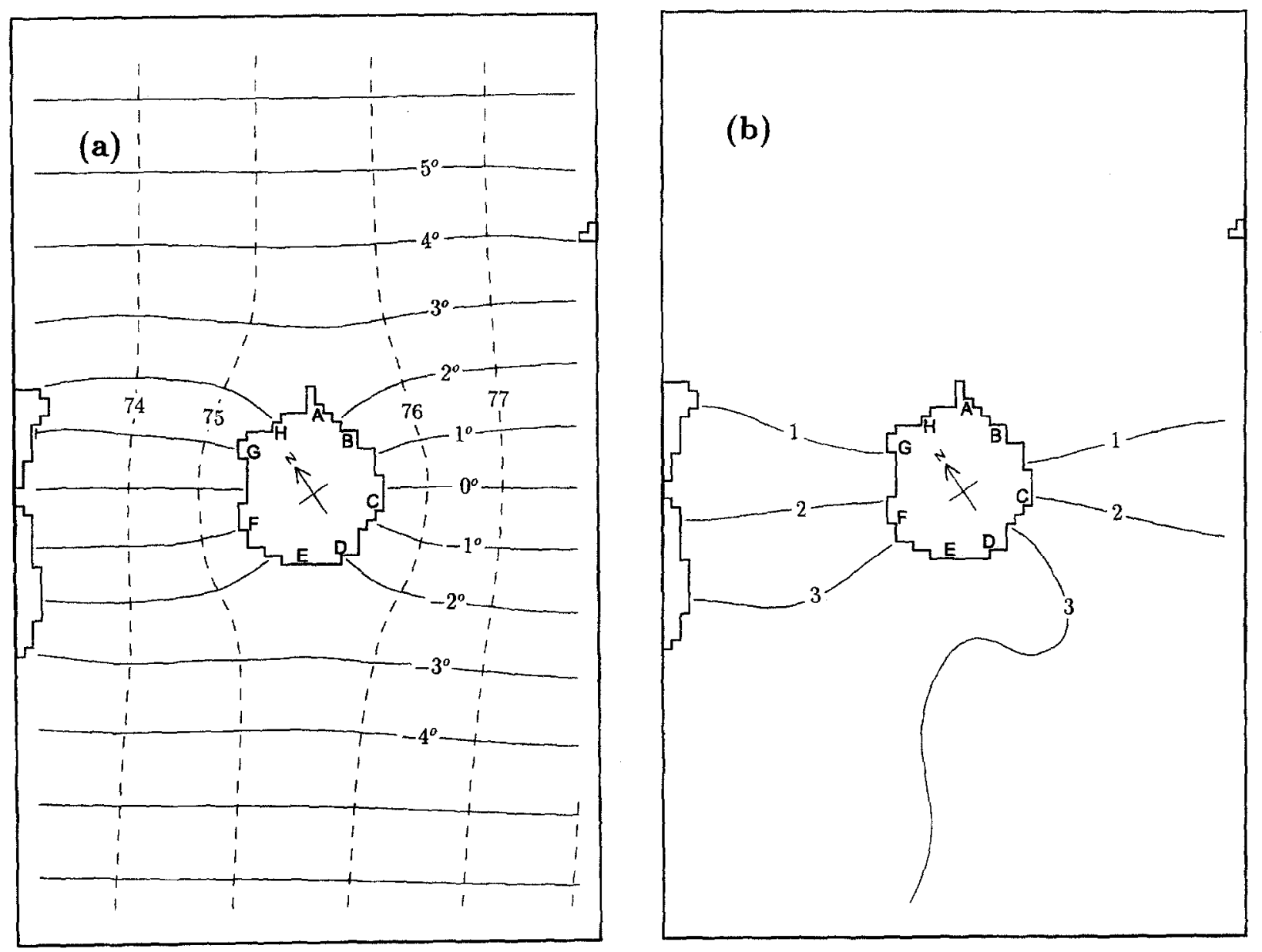

Figure 4. Numerical results for the case of Gran Canaria Island with uniform depth. (a): result for $\eta$. Continuous lines: phases. Dashed lines: Amplitudes (cm). (b): Percentage of standing wave $([W p /(W p+W s)] \times 100)$.

ferences scheme (leapfrog type) on a rectangular Arakawa$\mathrm{C}$ grid, already used in a previous study [14]. A 2625 by $2625 \mathrm{~m}$ grid resolution was used with the longitudinal axis oriented along $34^{\circ}$ with respect to the north, which is approximately the direction of current oscillations observed in the open ocean [25]. A maximum water depth of $3000 \mathrm{~m}$ and a time step of $\Delta t=3.2 \mathrm{~s}$ were given to satisfy the Courant-Friederichs-Lewy (CFL) stability requircment [6].

The southeastern and northwestern boundaries of the model were assumed to be solid walls. Zero normal velocity was imposed at land boundaries and at the two solid walls of the channel. The model had an open boundary condition at its northeastern and southwestern extremes. At the ingoing boundary (southwest) the surface elevation produced by the Kelvin wave was specified, and along the outgoing boundary (northeast) the
Sommerfeld condition was used to make it transparent to the Kelvin waves [3]. This channel model is the usual approximation to study any effect produced by a sudden change in topography over a Kelvin wave $[8,26]$. This condition ensures that the only possible mode at a certain distance from the island is the Kelvin wave. In the this case, the reflection of the scattered waves on the solid walls affects the numcrical solution around the island if the walls are not sufficiently separated. The procedure adopted to minimize this effect consists of progressively widening the channel to the point where the differences between successive experiments are negligible.

Two cases have been studied to separate the factors that determine the behaviour of the semidiurnal tide at the island shelf: (a) Gran Canaria with uniform depth of $3000 \mathrm{~m}$; and (b) Gran Canaria with real bathymetry to a 



Figure 5. Numerical results for the case of Gran Canaria Island with real bathymetry. (a): amplitudes in cm (dashed lines) and phases (continuous lines) for $\eta$. (b): semi-major axis in $\mathrm{cm} \mathrm{s}^{-1}$.

maximum depth of $3000 \mathrm{~m}$. The grid chosen was different for each case such that the presence of the channel walls had a minimum effect in the results around the island. In case (a), a $525 \mathrm{~km}$ length by $181 \mathrm{~km}$ wide grid, which fits the region between the neighbouring islands of Tenerife and Fuerteventura, was used. For case (b), it was necessary to increase the dimension to 929 by $469 \mathrm{~km}$, considering a uniform depth of $3000 \mathrm{~m}$ remote from the region of study.

The tidal motion was generated from an initial state of rest $(\eta=u=v=0)$. This condition generates errors that disappear after a transitory time period [4]. Since the time-periodic solution has a cycle of $12.4206 \mathrm{~h}$, the effect of starting errors can be evaluated by comparing the water level and velocities computed at a given instant with those computed $12.4206 \mathrm{~h}$ earlier. After a 20-day simulation, the time at which the periodic solution was found to be stable, the model was run continuously for five additional days. Time series, including hourly values of elevation and velocity components were extracted at each active computational point. The results were then subjected to an harmonic (least square) tidal analysis to evaluate the amplitudes and phase lags.

Additional experiments were performed to ascertain the importance of the nonlinear terms present in the equations (3)-(5). The equations were first solved without those terms, later retaining the bottom friction terms, and finally also including the convective terms. The results showed that the quadratic friction terms barely modify the solution. The convective terms created overtides and residual currents on the insular shelf. The residual currents were seen to be highly affected by the discretization of the coastal grid, indicating that it is necessary to use very good grid resolution around the island to solve it correctly. Nevertheless, the convective terms only produce very slight differences on the principal wave $\left(M_{2}\right)$ whose behaviour is analysed in the next section. 

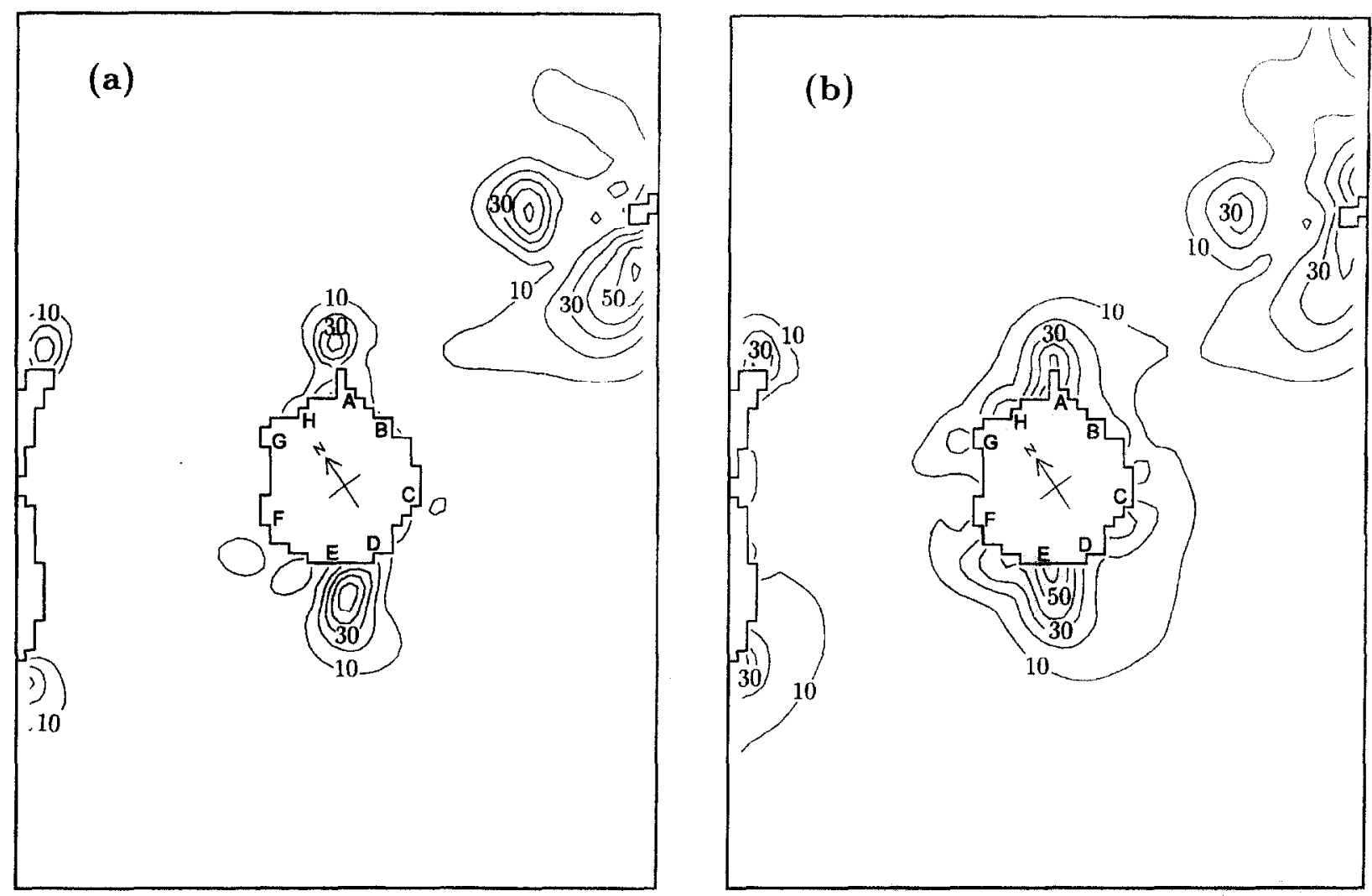

Figure 6. Numerical results for the case of Gran Canaria island with real bathymetry. (a): ellipticity ( $m / M)$. (b): percentage of standing wave.

\section{NUMERICAL RESULTS AND COMPARISON WITH OBSERVATIONS}

Figure $4 a$ shows the water level amplitude and phase results of the numerical experiment for the case of uniform depth. The amplitudes of the Kelvin wave at the ingoing boundary were chosen such that the values around the island were about $75.5 \mathrm{~cm}$. The result is similar to that obtained for a perfect cylinder, although with some deformation due to the precise geometry of the island. The current results also show a similar pattern to that of the analytical solution (not shown). The currents around the island are oriented parallel to the local direction of the coast. The maximum values were obtained at the southeast and northwest. Figure $4 b$ shows that the standing wave ratio $W s /(W s+W p)$ is very small (maximum $3 \%$ ) for the present case.

The result of the experiment with real bathymetry is depicted in figures 5,6 . The amplitude and phase results of $\eta$ are presented in figure $5 a$, which shows that the perturbation of the incident Kelvin wave is more important than that from the case of uniform depth. It decreases rapidly away from each island, indicating that variations of the tidal properties around the Gran Canaria Island are less affected by the presence of the neighbouring islands. The presence of the insular shelf produces a $2^{\circ}$ variation of the phase between the northeastern and the southwestern island sides, larger than in the case of plane depth. While in the case of uniform depth the amplitudes around the island were constant, in the case being discussed here the bathymetry produces a change in the amplitudes. A minimum of $74 \mathrm{~cm}$ is found northeast of the island and a maximum of $77 \mathrm{~cm}$ is located southwest.

The result of the level data analysis (table II) shows a strong variation of the semidiurnal amplitude between the northeastern and the southwestern parts of Gran Canaria. The amplitudes to the north coincide with the expected values for the ocean tides in this part of the Atlantic, indicating that the phenomenon consists of a diminution of the amplitudes at the southwest of the island (stations $E$ and D). The model results shown in figure $5 a$ can explain the smaller amplitudes observed at station B with respect 
to station A. However, these results do not agree with the amplitude diminution at the southwest. The fact that the shelf is wider and shallower in the southwest may indicate that the measured lower amplitudes are due to local small-scale effects. Therefore, it would be necessary to use a numerical model with a grid of very fine resolution around the island and with more realistic boundary conditions in order to investigate this feature.

Figure $5 b$ shows the variation of the semi-major axes around the island. The maximum axes are located in the southeast and northwest, but their magnitudes are considerably higher than those obtained for the case of uniform depth due to the enhancement effect of the shallow waters. This result qualitatively explains the variations observed in section 3 . The shallow waters also produce important tidal currents south of Fuerteventura and at the Amanay Seamount.

The change in depth yields the appearance of semi-minor axes and the model gives the highest eccentricities $(\mathrm{m} / \mathrm{M})$ south of Fuerteventura and over the Amanay Seamount (figure 6a). The major eccentricities around Gran Canaria are found over the insular slope where the wave goes through the bathymetry (northeast and southwest of the island). The percentage of the wave which is explained by the standing wave is presented in figure $6 b$. The figure illustrates a pattern that reflects the existence of two maxima close to $60 \%$, located in the coastal regions where the wave arrives and leaves, and of two minima at both sides (southeast and northwest). This result reproduces approximately the current phase variations observed at the insular shelf. The combined figures $6 a$ and $6 b$ indicate that near the coast the shallow water amplifies the currents when they flow parallel to the coast. In the northeastern and southwestern parts of the island, this takes place a quarter of a wave period before and after the high water occurrence moment, while in the northwest and southeast the maximum currents occur at the same time as the high waters. Furthermore, the numerical results suggest analogous behaviour at Tenerife and Fuerteventura.

\section{CONCLUSIONS}

The first objective of this study was to provide, through the analysis of field data, a quantitative description of the tidal elevations and currents around Gran Canaria. The results show the following characteristics:

(a) The progression of tidal level constitucnts is approximately from south to north, confirming the indications given by the tidal charts for the area. Semidiurnal ampli- tudes and phases at the stations located north and northeast of the island coincide with the expected values from such charts ( $75-76 \mathrm{~cm}$ for $M_{2}$ ). However, the amplitudes suffer an important diminution at the southern and southwestern stations. This effect is not produced in the case of diurnal constituents which are less disrupted by the island.

(b) The semi diurnal semi-major axes are smaller in those regions where the waves arrive and leave, northeast and southwest, but considerably larger in the lateral regions (southeast and northwest). Furthermore, in the former regions the semidiurnal constituents have a near-standing character while in the latter ones they resemble progressive waves.

The analytical approximation obtained for the diffraction of a Kelvin wave at a cylinder and the numerical solution for the case of Gran Canaria with uniform depth show that the distortions of the semidiurnal waves (amplitudes and phases) are small, with the amplitudes being constant around the island. The result obtained in the case of real bathymetry does not explain the observed amplitude diminution southwest of the island. Probably, this is because the model grid does not have sufficient resolution to solve this local effect. However, the resolution is sufficient to reveal that the island shelf is responsible for the amplitude variation around the island. This result, together with the observed variation of semidiurnal amplitudes around the island, highlights the necessity of taking into account the insular shelves in the estimation of representativeness of island tidal measurements.

The numerical results for currents reproduce the variations of the semidiurnal current properties observed at the insular shelf. They show the amplification of the currents at the southeast and northwest of the island produced by the enhancement effect of shallower waters around the island. They also show that the standing and progressive characters observed around the island are due to the presence of the shelf, which increases the eccentricity of the current ellipses near the slope and amplifies the standing character at the southwestern and northeastern parts of the shelf.

\section{Acknowledgements}

The authors wish to thank Gabriel Godin for useful discussions. This work was supported by Fundación Universitaria de Las Palmas and Astilleros Canarios S.A., and by the Spanish Government (CICYT) through grant AMB95-0731. 
[1] Abramowitz M., Stegun A., Handbook of mathematical functions, Dover Publications, Inc., 1965, 1046 p.

[2] Andersen O.B., Woodworth P.L., Flather R.A., Intercomparison of recent ocean tide models, J. Geophys. Res. 100 (1995) $25,261-25,282$.

[3] Bills P, Noye J., An investigation of open boundary condition for tidal models of shallow seas, in: J. Noye (Ed.), Numerical modelling: applications to marine systems, Elsevier, NorthHolland, 1987, $295 \mathrm{p}$.

[4) Bode L., Sobey R.J., Initial transients in Long Wave Computations, J. Hydr. Engineer, ASCE 110 (2) (1984) 237-255.

[5] Cartwright D.E., Ray R.D., Oceanic tides from Geosat altimetry, J. Geophys. Res. 95 (1991) 3069-3090.

[6] Courant R., Friedrichs K., Lewy H., Über die partiellen Differenzengleichungen der mathemathischen Physik, Math. Annalen 100 (1928) 32-74.

[7] Dick G., Siedler G., Barotropic tides in the northeast Atlantic inferred from moored current meter data, Dtsch. Hydrogr. Z. 38 (1985) 7-22.

[8] Falconer R.A., Wolanski E., Mardapitta-Hadjipandeli L., Modeling tidal circulation in an island's wake. J. Water., Port, Coast. and Ocean Engineer, ASCE 112 (2) (1986) 234-254.

[9] Foreman M.G.G., Manual for tidal heights analysis and prediction, Pacific Marine Science Report 77-10, Inst. of Ocean Sciences, Patricia Bay (1977).

[10] Foreman M.G.G., Manual for tidal currents analysis and prediction, Pacific Marine Science Report 786, Inst. of Ocean Sciences, Patricia Bay (1978).

[11] Godin G., The analysis of tides, University of Toronto Press, $1972,264 \mathrm{p}$.

[12] Godin G., The use of the admittance function for the reduction and interpretation of tidal records, Marine Environmental Data service, MS Report (1976) 91p.

[13] Godin G., The analysis of tides and currents, in: Parker B.B. (Ed.), Tidal Hydrodynamics, J. Wiley, 1991, 675-709.
[14] Godin G., Martinez A., On the possibility of Kelvin-type motion in actual seas, Cont. Shelf Res. 14 (1994) 707-721.

[15] Huthnance J.M., Baines P.G., Tidal currents in the northwest African upwelling region, Deep-Sea Res. 20 (1982) 285-306.

[16] Kagan B.A., Kivman G.A., Modelling of global ocean tides with allowance for island effects, Dtsch. Hydrogr. Z. 1 (1993) $1-13$.

[17] Kagan B.A., Kivman G.A., A necessary condition for the representativeness of island tidal measurements, J. Geophys. Res. 100 (1995) 11,047-11,051.

[181 Lamb H., Hydrodynamics, Cambridge Univ. Press (1932) $738 \mathrm{p}$.

[19] Larsen J.C., Cotidal charts for the Pacific Ocean near Hawaii using f-plane solutions, J. Phys. Oceanogr. 7 (1977) 100-109.

[20] Le Provost C., On the use of sea level gauge data for satellite altimetry validation: A review, Oceanol. Acta 15 (1992) 431440 .

[21] Le Provost C., Genco M.L., Lyard F., Vincent P., Canceil P., Spectroscopy of the world ocean tides from a finite element hydrodynamic model, J. Geophys. Res. 99 (1994) 2477724797.

[22] Proudman J., Diffraction of tidal waves on flat rotating sheets of water, Proc. Lond. Math. Soc. 15 (1914) 89-102.

[23] Pugh D.T., Vassie J.M., Tide and surge propagation off-shore in the Dowsing region on the North Sea, Dtsch. Hydrogr. Z., 29 (1976) 361-372.

[24] Schwiderski E.W., On charting global ocean tides, Rev. Geophys. 18 (1980) 243-268.

[25] Siedler G., Paul U., Barotropic and baroclinic tidal currents in the eastern basins of the north Atlantic, J. Geophys. Res. 96 (1991) 22259-22271.

[26] Tee K.T., Dynamics of a two-dimensional topographic rectification process, J. Phys. Oceanogr. 4 (1994) 443-465.

[27] Tejedor B., Fenómenos dinámicos de interacción atmósferaoceano, Ph.D Thesis, Univ. Las Palmas de Gran Canaria (1991) $289 \mathrm{p}$. 